\title{
Heterocyclic Hypervalent Iodine(III) Compounds with Fused Benziodazole and Tetrazole Rings (I-Substituted Tetrazolo[1,5-b][1,2]Benziodazoles)
}

Rajesh Kumar, ${ }^{1,}$ Kapil Dev Sayala, ${ }^{1,}{ }^{\#}$ Lejla Camdzic, ${ }^{1}$ Maxime Siegler, ${ }^{2}$ Avichal Vaish, ${ }^{1}$ and Nicolay V. Tsarevsky, ${ }^{1, *}$

${ }^{1}$ Department of Chemistry, Southern Methodist University, Dallas, TX 75275, USA

${ }^{2}$ Department of Chemistry, Johns Hopkins University, Baltimore, Maryland 21218, USA

*Corresponding author. Email: nvt@smu.edu

${ }^{\#}$ R.K. and K.D.S. contributed equally to this work.

\begin{abstract}
A series of heterocyclic hypervalent (HV) iodine(III) compounds containing fused tetrazole and benziodazole rings, i.e., derivatives of benziodazolotetrazole (BIAT) with various ligands attached to the iodine atom were prepared and studied. 5-Chloro-5H-5 $\lambda^{3}$-tetrazolo[1,5-b][1,2]benziodazole (BIAT-Cl) was synthesized via chlorination of 5-(2-iodophenyl)-1H-tetrazole and subsequent spontaneous cyclodehydrochlorination of the initially formed dichloroiodo compound. The oxidation of the aforementioned parent monovalent iodine substrate with $\mathrm{NaIO}_{4}$ yielded 5-hydroxy-5H-5 $\lambda^{3}$-tetrazolo[1,5b][1,2] benziodazole (BIAT-OH), which was in turn reacted with acetic anhydride to afford the $I$-acetoxy derivative (BIAT-OAc). 5-Methoxy-5H-5 $\lambda^{3}$-tetrazolo[1,5 b][1,2]benziodazole (BIAT-OMe) was obtained by refluxing the latter compound or by dissolving (2-(1H-tetrazol-5-yl)phenyl)(hydroxy)iodonium tosylate in methanol. All heterocyclic $\mathrm{HV}$ iodine(III) compounds were characterized by ${ }^{1} \mathrm{H}$ and ${ }^{13} \mathrm{C}$ NMR spectroscopy, ESI-HRMS, and X-ray crystallography. The reaction of various alkenes with BIAT-Cl in the presence of $\mathrm{Cu}(\mathrm{OTf})_{2}$ at room temperature yielded chloro-tetrazolylated products. The oxidation of thioanisole with BIAT-Cl under various reaction conditions is also reported. The thermal stabilities of all BIAT derivatives were examined as well. The enthalpies of exothermic degradation were measured by
\end{abstract}


thermal gravimetric analysis coupled with differential scanning calorimetry and were determined to be in the range between -209 and $-644 \mathrm{~J} \mathrm{~g}^{-1}$, i.e., significantly larger than the enthalpy of decomposition (-108 $\mathrm{J}$ $\left.\mathrm{g}^{-1}\right)$ of the parent monovalent iodine-containing tetrazole - 5-(2-iodophenyl)-1H-tetrazole.

\section{INTRODUCTION}

The organic compounds of polyvalent iodine were discovered in 1886 by Willgerodt who showed that the chlorination of iodobenzene afforded a yellow crystalline solid, (dichloroiodo)benzene $\mathrm{C}_{6} \mathrm{H}_{5} \mathrm{ICl}_{2}{ }^{1}$ Within several years, numerous additional organic compounds of both iodine(III) and (V) were reported, and the first monograph on the subject, by Willgerodt, published in 1914, contained hundreds of examples. The molecular structures of these compounds and especially the nature of the bonds involving the polyvalent iodine atom have been of significant interest to physical organic and theoretical chemists since at least the 1930s when the crystal structures of salts with iodine-containing polyhalide anions (e.g., triodide $^{2}$ and dichloroiodide ${ }^{3}$ ) were analyzed. These early structural studies became the inspiration for the first proposed bonding models, in which the p-orbitals (but not the d-orbitals) of the central polyvalent halogen were involved. ${ }^{4,5}$ The most noticeable feature of $\mathrm{HV}$ iodine molecules is the presence of the almost linear fragment(s) L-I-L', where L and L' are electronegative ligands bonded to the tri- or pentavalent iodine atom via 3 -center-4-electron $(3 \mathrm{c}-4 \mathrm{e})$ bonds, dubbed hypervalent (HV) bonds. ${ }^{6}$ These bonds are weaker than the "classical" covalent (2c-2e) bonds and are responsible for the unique reactivity of HV iodine(III) and (V) compounds as electrophiles, radical sources (after homolysis of the HV bonds), and oxidants. Typical examples of $\mathrm{L}$ and L' include halide (fluoride and chloride), $O$-ligands (such as carboxylate, phsphonate, and sulfonate), $N$-ligands (e.g., azide or other pseudohalides, amide, and terazolylate), as well as perfluoralkyl groups. The major aspects of the structural and applied chemistry of HV iodine(III) and (V) compounds, including their utility in organic and polymer synthesis, have been summarized in several monographs ${ }^{7-11}$ and review papers. ${ }^{12-23}$ 
There are numerous examples where one of the ligands and the iodine atom are a part of a ring, typically five-membered, which, in most known examples, is fused with an aromatic one (e.g., benzene). In fact, the existence of heterocyclic HV iodine(III) compounds was first suggested in 1892 when Meyer and Wachter studied the oxidation of 2-iodobenzoic acid, ${ }^{24}$ which yields $I$-hydroxybenziodoxolone 1c (Scheme 1). The chlorination of the same acid affords the corresponding yellow dichloroiodo compound 1a, which, upon drying, undergoes rapid and spontaneous cyclo-dehydrochlorination to the heterocyclic compound $\mathbf{1 b} .^{25-27}$ The formation of a HV iodine-containing heterocycle fused with an aromatic ring leads to marked stabilization due to the bridging of the equatorial and apical positions at the HV center, ${ }^{28}$ as well as the improved overlap of the nonbonding electrons at the HV iodine(III) atom with the $\pi$-orbitals of the conjugated aromatic system. ${ }^{13}$ The stability of five-membered I-O heterocycles is the chief reason why benziodoxoles with I-F, ${ }^{29-32} \mathrm{I}-\mathrm{Br},{ }^{33} \mathrm{I}-\mathrm{OR},{ }^{34-36} \mathrm{I}-\mathrm{OOR},{ }^{37-40} \mathrm{I}-\mathrm{N}_{3},{ }^{41-43} \mathrm{I}-\mathrm{CN},{ }^{43-45}$ and $\mathrm{I}-\mathrm{CF}_{3}{ }^{31,46}$ bonds could be easily prepared and isolated, despite the fact that many of the corresponding acyclic analogues with the same ligands decompose readily. The reactivity and single-crystal X-ray crystal structures of benziodoxoles have been studied in great detail and summarized in several reviews. ${ }^{11,20,47}$ In general, benziodoxoles have a planar structure with distorted T-shaped geometry around the HV iodine atom. More recent examples of I-O heterocyclic compounds include benziodoxaboroles, ${ }^{48}$ benziodoxathioles, ${ }^{49,50}$ and cyclic phosphonates. ${ }^{51}$ In 1965, Wolf and Steinberg reported another class of heterocyclic HV iodine(III) compounds, the benziodazoles, in which the I(III) atom is bonded to a nitrogen atom in a five-membered ring fused to a benzene ring. ${ }^{52}$ The first example of a crystal structure was that of $I$-acetoxybenziodazole, ${ }^{53}$ but a large variety of $\mathrm{HV}$ I-N-heterocycles have since been discovered and studied. ${ }^{54}$ including benziodoxaboroles, ${ }^{48}$ benziodoxathioles,${ }^{49,50}$ and cyclic phosphonates. ${ }^{51}$

We recently demonstrated ${ }^{55}$ that tetrazolates $\mathrm{RCN}_{4}^{-}$, similarly to carboxylates $\mathrm{RCO}_{2}^{-}$, bind efficiently to HV iodine(III) centers. The synthesis, structural characterization, thermal degradation, electrochemical behavior, and reactivity were reported for a number of tetrazole-containing HV iodine(III) compounds with the general formula $\left.\mathrm{RCN}_{4}-[\mathrm{I}(\mathrm{Ar})-\mathrm{O})\right]_{\mathrm{n}}-\mathrm{I}(\mathrm{Ar})-\mathrm{N}_{4} \mathrm{CR}\left(\mathrm{R}=\mathrm{CH}_{3}, \mathrm{C}_{6} \mathrm{H}_{5}\right.$, or 4- $\mathrm{CH}_{3} \mathrm{C}_{6} \mathrm{H}_{4}$, and $\mathrm{n}$ 
$=0,1, \geq 2$; the compounds with $\mathrm{n}=0$ are the tetrazole analogues $\operatorname{Ar}\left(\mathrm{N}_{4} \mathrm{CR}\right)_{2}$ of (diacyloxyiodo)arenes $\left.\operatorname{ArI}\left(\mathrm{O}_{2} \mathrm{CR}\right)_{2}\right)$. Furthermore, we described the synthesis and characterization of an $N$-tetrazole-stabilized pseudocyclic HV iodine(III) compound, (2-(1H-tetrazol-5-yl)phenyl)(hydroxy)iodonium tosylate. ${ }^{56}$

Herein, we report that 5-(2-iodophenyl)-1H-tetrazole 2 can be successfully employed for the synthesis of compounds with the benzoiodazolotetrazole (BIAT) cyclic structure (consisting of fused tetrazole and benziodazole rings) with various ligands bonded to the HV iodine(III) center. The structures, reactivities, and exothermic decomposition of these new compounds were studied and are presented as well.

\section{RESULTS AND DISCUSSION}

Benziodoxolones 1b-f with I-Cl, ${ }^{57,58} \mathrm{I}-\mathrm{OH},{ }^{57} \mathrm{I}-\mathrm{O}_{2} \mathrm{CR},{ }^{34}$ and $\mathrm{I}-\mathrm{OMe}^{34}$ bonds can be easily prepared from 2-iodobenzoic acid, as shown in Scheme 1a. There are multiple similarities between carboxylic acids $\left(\mathrm{RCO}_{2} \mathrm{H}\right)$ and tetrazoles $\left(\mathrm{RCN}_{4} \mathrm{H}\right)$, including their acidities, the coordination ability of the corresponding anions $\mathrm{RCO}_{2}^{-}$and $\mathrm{RCN}_{4}^{-}$, and stereochemical resemblance (e.g., including bond lengths, valence angles, and the planar structure, as well as the distances between the substituents $\mathrm{R}$ and $\mathrm{R}$ ' in esters $\mathrm{RCO}_{2} \mathrm{R}$ ' and the analogous 1,5-disubstituted tetrazoles $\left.\mathrm{RCN}_{4} \mathrm{R}^{\prime}\right)$. Inspired by these facts, along with our recent finding that the affinity of tetrazolates and carboxylates for HV iodine(III) atoms are similar, ${ }^{55}$ we investigated the possibility to use 5-(2-iodophenyl)-1H-tetrazole $\mathbf{2}$ as a precursor of compounds with fused benziodazole and tetrazole rings 3-8, designated BIAT-L ( $\mathrm{L}$ is the exocyclic ligand attached to the HV iodine(III) atom), as shown in Scheme $1 b$. 


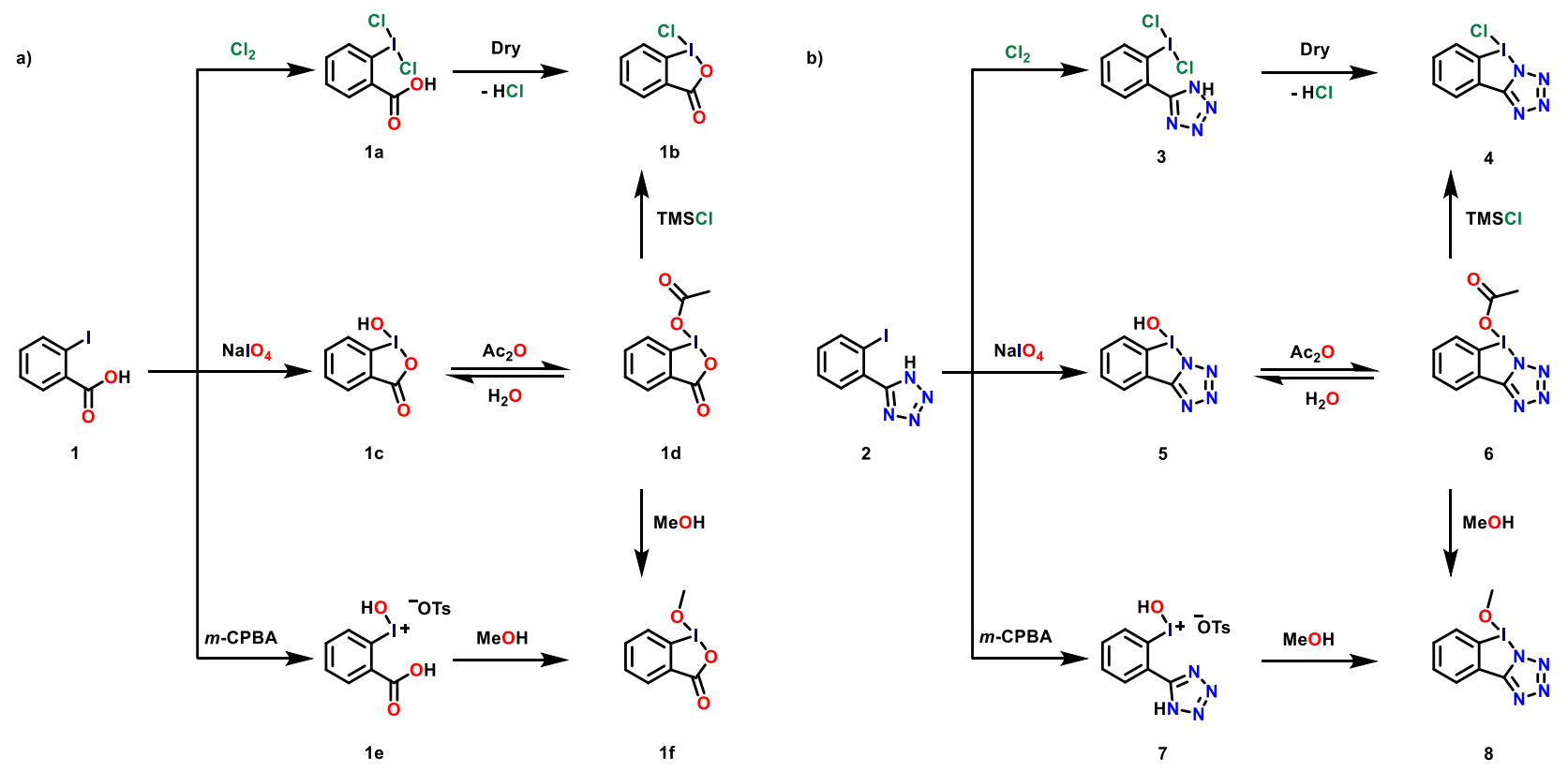

Scheme 1. Synthetic routes to known benziodoxoles (a) and analogous I-substituted HV iodine(III) compounds with fused tetrazole and benziodazole rings, i.e., BIAT-L compounds (b).

The precursor 2 was synthesized from 2-iodobenzonitrile and sodium azide, using a modified published procedure.$^{56} \mathrm{HV}$ iodine(III) compounds with $\mathrm{I}-\mathrm{Cl}$ bonds are of interest since they have found numerous applications in organic synthesis as efficient chlorinating and oxidizing agents, ${ }^{59}$ as well as chain transfer reagents in radical (e.g., polymerization) reactions. ${ }^{60}$ Initially, the possibility was investigated to prepare BIAT-Cl $\mathbf{4}$ by chlorination of $\mathbf{2}$, followed by cyclo-dehydrochlorination of the produced dichloroiodo compound $\mathbf{3}$, which, in analogy with the transformations that 2-iodobenzoic acid undergoes under similar conditions, was expected to be slow in solution in acetic acid but spontaneous and fast in the solid-state. Indeed, when the monovalent iodine precursor 2 was chlorinated with $\mathrm{SO}_{2} \mathrm{Cl}_{2}$ (an easy to use alternative to chlorine ${ }^{61}$ ) in acetic acid, ${ }^{62}$ the formation of 2-(dichloroiodo)benzyltetrazole 3 was deduced visually (appearance of yellow color, typical of compounds containing the $-\mathrm{ICl}_{2}$ group) and ascertained by NMR spectroscopy (Figures 1a and S1). The yields of $\mathbf{3}$ were low even when the reaction was carried out with an excess of $\mathrm{SO}_{2} \mathrm{Cl}_{2}$. For instance, when 4 eq. of the chlorinating agent vs. the iodocompound 2 were employed, only a small amount of $\mathbf{3}$ was formed (ca. $25 \%$, Figure 1b). The yield did not increase at longer 
reaction times, most likely due to the establishment of an equilibrium between $\mathbf{2}$ and $\mathbf{3}$ characterized with a comparatively low equilibrium constant (similar to equilibria between other iodo- and dichloroiodo compounds ${ }^{63}$ ). More in-depth kinetic studies of the conversion of 2 to 3 (Figure $1 b$ ) confirmed that the degrees of chlorination were limited, even when a large excess of the chlorinating agent (e.g., 50 eq.) vs. the aryl iodide precursor was employed. In all cases, the formation of dichloroiodocompound $\mathbf{3}$ took less than $1 \mathrm{~h}$, even at low concentrations of the starting reactant 2 (e.g., $10 \mathrm{mM}$ used in the spectral studies) and the compound was stable in solution in acetic acid, i.e., no formation of BIAT-Cl was observed. (The NMR spectral characteristics of the acyclic and the cyclic HV iodine(III) compounds are distinct (Figure 1a) and allow for the occurrence of cyclization to be examined.)

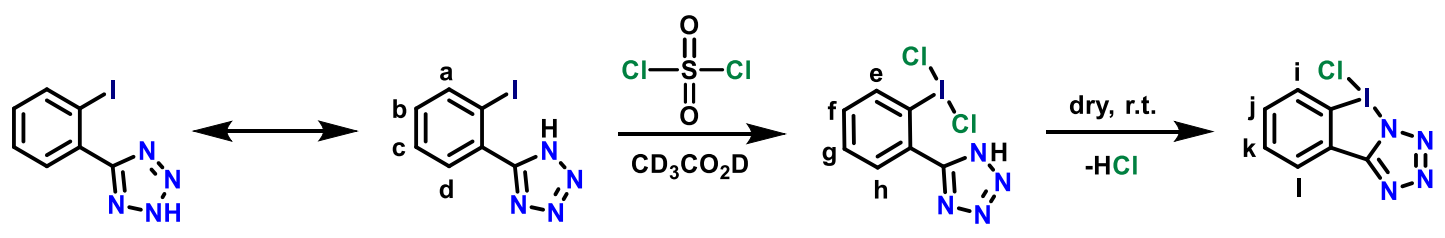

2

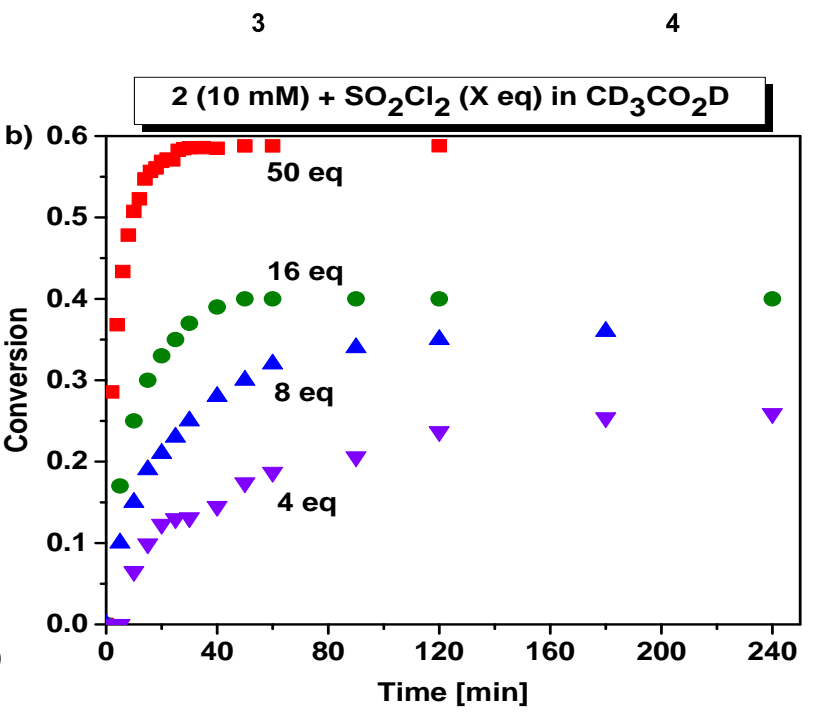

Figure 1. Evolution of ${ }^{1} \mathrm{H}$ NMR spectra during the chlorination of 2 to 3 with $\mathrm{SO}_{2} \mathrm{Cl}_{2}\left(50\right.$ eq) in $\mathrm{CD}_{3} \mathrm{CO}_{2} \mathrm{D}$ (a) and kinetics of conversion of $\mathbf{2}$ to $\mathbf{3}$ in the presence of variable amounts (with the number of eq indicated) of $\mathrm{SO}_{2} \mathrm{Cl}_{2}$ (b). 
HV iodine(III) compounds with I-Cl bonds can also be prepared by alternative chlorination procedures. For instance, $\mathrm{Cl}_{2}$ can be conveniently generated in situ in the reaction between sodium chlorite $\left(\mathrm{NaClO}_{2}\right)$ and concentrated $\mathrm{HCl} \cdot{ }^{64,65}$ This methodology gave the desired product 4 in $70 \%$ yield in $16 \mathrm{~h}$ (Table 1, entry 2) as a light yellow powder. At first, the dichloroiodo derivative $\mathbf{3}$ was obtained as intensely yellow-colored material, which rapidly lost $\mathrm{HCl}$ upon drying and acquired paler yellow color. Another pathway to synthesize BIAT-Cl $\mathbf{4}$ was the reaction of the monovalent iodine compound $\mathbf{2}$ with trichloroisocyanuric acid (TCICA) - a procedure that has been successfully utilized by Togni ${ }^{31}$ and Xiao ${ }^{66}$ in the preparation of various chloroiodanes. The side product of this reaction, isocyanuric acid, is insoluble in the reaction medium and can be removed by simple filtration. A suspension of 2 and TCICA in acetonitrile was refluxed for $10 \mathrm{~min}$ and filtered while hot. The solution was concentrated, and the resulting solid was collected by filtration. After washing with cold acetonitrile, the targeted compound $\mathbf{4}$ was isolated (Table 1, entry 3) and found to be reasonably stable at room temperature. It could be stored for several weeks in a refrigerator $\left(-20^{\circ} \mathrm{C}\right)$ in the absence of light without noticeable degradation. However, the compound is thermally unstable and decomposes explosively when heated to $c a .137{ }^{\circ} \mathrm{C}$ (see video in the Supporting Information (SI)). In addition, it is extremely reactive towards reducing agents - even mild ones. For instance, the reaction of BIAT-Cl with both tribuylphosphine (moderately strong reducing agent) and DMSO (weakly reducing) is violent (see video in the SI). BIAT-Cl degrades readily in polar solvents, such as DMF and $\mathrm{CH}_{3} \mathrm{CN}$, as well as - as mentioned - in DMSO (Figure S2) and was found to be insoluble in many common solvents, which hampered further structural studies.

Table 1. Summary of chlorination reactions of 2 at $25^{\circ} \mathrm{C}$ under different conditions.

\begin{tabular}{lllll}
\hline$\#$ & Reagent (eq vs 2) & Solvent & Time [h] & Yield [\%] \\
\hline 1 & $\mathrm{SO}_{2} \mathrm{Cl}_{2}(50)$ & $\mathrm{CH}_{3} \mathrm{CO}_{2} \mathrm{H}$ & 1 & $60^{a}$ \\
2 & $\mathrm{NaClO}_{2}(3)+\mathrm{HCl}(2)$ & $\mathrm{H}_{2} \mathrm{O}$ & 16 & $70^{b}$ \\
3 & TCICA (0.6) & $\mathrm{CH}_{3} \mathrm{CN}$ & 0.17 & $65^{b}$ \\
\hline
\end{tabular}

${ }^{a}$ Yield of $\mathbf{3}$ as calculated by ${ }^{1} \mathrm{H}$ NMR spectroscopy. ${ }^{b}$ Isolated yield of $\mathbf{4}$. 
The monovalent iodine compound $\mathbf{2}$ was also successfully oxidized with $\mathrm{NaIO}_{4}$ in aqueous acetic acid $(30 \%(\mathrm{v} / \mathrm{v}))$ under reflux for $4 \mathrm{~h}$ (Scheme 1b). Upon cooling, brown crystals of 5-hydroxy-5H-5 $\lambda^{3}-$ tetrazolo[1,5-b][1,2]benziodazole, BIAT-OH 5, were obtained. The crystals were washed with large amounts of diethyl ether to remove the starting materials and other byproducts, and were analyzed by ${ }^{1} \mathrm{H}$ and ${ }^{13} \mathrm{C}$ NMR spectroscopy, ESI-HRMS, and single-crystal X-ray crystallography. The crystal structure of BIAT-OH is presented in Figure 2.

a)

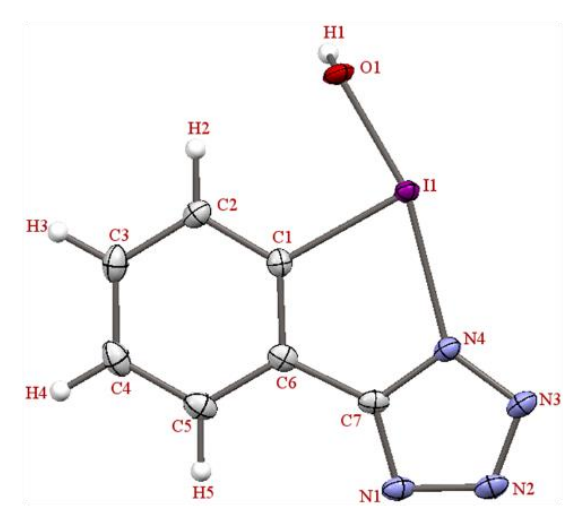

b)

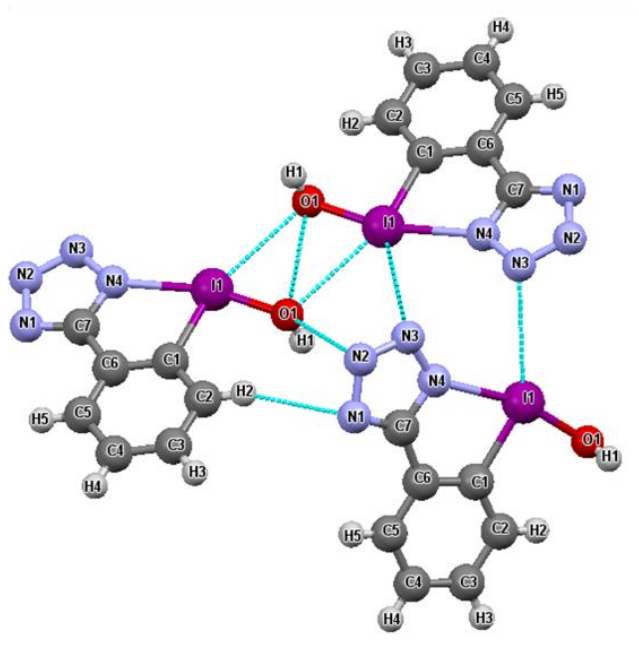

Bond distances $[\AA]$

I1-O1 1.97

I1-N4 $\quad 2.37$

I1-C1 2.13

Bond angles [ $\left.{ }^{\circ}\right]$

O1-I1-C1 89.62

N4-I1-C1 74.54

N4-I1-O1 164.16

I1-N4-C7 111.86

Interatomic distances $[\AA]$

I1-N3 3.33

I1-O1 3.00

N2-O1 $\quad 3.01$

$\mathrm{N} 1-\mathrm{H} 2$

Figure 2. (a) Crystal structure of 5-hydroxy-5H-5 $\lambda^{3}$-tetrazolo[1,5-b][1,2]benziodazole 5 (ellipses are shown at 50\% probability) with selected bond lengths and angles. (b) Intra- and intermolecular secondary bonding in $\mathbf{5}$.

The iodine centers in both independent molecules present in the unit cell of 5 have the characteristic distorted T-shaped geometry around the iodine center with the valence angle of N-I-O being $164.16^{\circ}$. The HV I-O bond in 5 (1.97 $\AA$ ) was determined to be markedly (by 7-10\%) shorter than the HV I-O bonds in compounds containing acetoxy ligands, e.g., both in the acyclic compounds $\left.\mathrm{I}_{2} \mathrm{O}_{2} \mathrm{CCH}_{3}\right)_{3}$ (where the lenghts of the HV I-O bonds are in the range 2.16-2.17 $\AA)^{67}$ and $\mathrm{C}_{6} \mathrm{H}_{5} \mathrm{I}\left(\mathrm{O}_{2} \mathrm{CCH}_{3}\right)_{2}(2.14-2.19 \AA),{ }^{68}$ and in Iacetoxybenziodoxolone (where the length of exocyclic HV I-O bond is $2.11 \AA$ ).${ }^{69}$ However, it is comparable and only marginally shorter than the exocyclic HV I-O bond in the a related heterocylic compound with a 
hydroxy ligand, $I$-hydroxybenziodoxolone $(2.00 \AA),{ }^{70}$ and in the even more closely related benziodazole with methoxy ligands $(2.23 \AA) .{ }^{54}$ More noteworthy is the length of the endocyclic I-N bond $(2.37 \AA)$, which was markedly longer than the I-N bonds in a bicyclic benziodazole with two HV I-N bonds $\left(2.18 \AA\right.$ each), ${ }^{71}$ I-chlorobenziodoazole $(2.11 \AA),{ }^{72}$ I-chlorosulfoximine $(2.10 \AA), I$-trifluoromethylsulfoximine $(2.28 \AA),{ }^{73}$ and $I$-acetoxybenziodoazole $(2.10 \AA) .{ }^{53}$ At the same time, the I-N bond in BIAT-OH 5 is shorter than I-N bonds with pronounced ionic character, e.g., in I-phenylbenziodazole (2.45), ${ }^{74}$ and other compounds with pyridine coordinated to the HV iodine(III) atom (2.41-2.44 $\AA$ ). ${ }^{75}$ Several weak intermolecular contacts such as N2-O1, O1-I1, and I1-N3 were observed, which contributed to the formation of the dimeric assembly.

Polyvalent iodine compounds with one or more acyloxy (typically - acetoxy) ligands are among the most studied and widely used in practice. ${ }^{20}$ They are commonly prepared by reacting iodosyl compounds or HV iodine(III) compounds with I-OH bonds with acid anhydrides. Thus, when $\mathbf{5}$ was refluxed in acetic anhydride for $15 \mathrm{~min}$, the original heterogeneous mixture turned into a brown solution, which, upon cooling to $-20{ }^{\circ} \mathrm{C}$, afforded an off-white microcrystalline compound, 5-acetoxy-5H-5 $\lambda^{3}$-tetrazolo[1,5b] $[1,2]$ benziodazoles or BIAT-OAc 6, which was identified spectroscopically $\left({ }^{1} \mathrm{H}\right.$ and ${ }^{13} \mathrm{C}$ NMR as well as ESI-HRMS), and by single-crystal X-ray crystallography (Figure 3).

a)

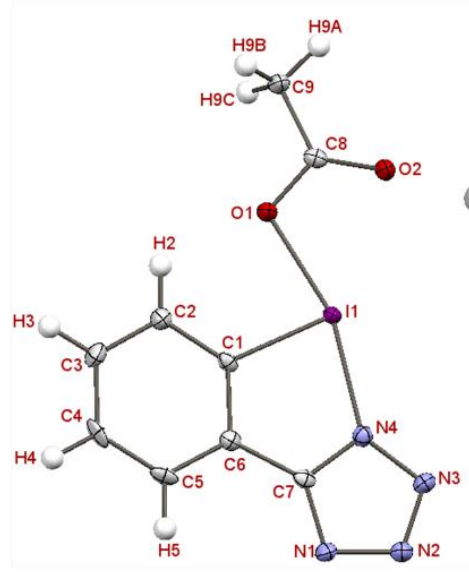

b)

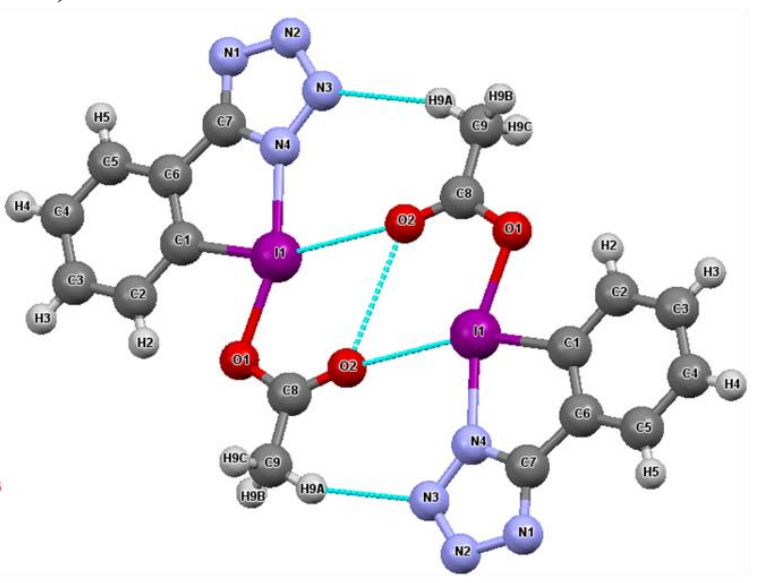

\begin{tabular}{|lc|}
\multicolumn{3}{|l|}{ Bond distances $[\AA]$} \\
I1-O1 & 2.14 \\
I1-N4 & 2.20 \\
I1-C1 & 2.12 \\
I1-O2 & 2.89 \\
\multicolumn{3}{|c|}{ Bond angles [0] } \\
O1-I1-C1 & 85.57 \\
N4-I1-C1 & 76.72 \\
N4-I1-O1 & 161.93 \\
I1-N4-C7 & 114.53 \\
\multicolumn{2}{|c|}{ Interatomic distances [A] } \\
I1-O2 & 2.88 \\
N1-H5 & 2.41 \\
N3-H9A & 2.54 \\
C8-N2 & 3.25 \\
\hline
\end{tabular}

Figure 3. (a) Crystal structure of 5-acetoxy-5H-5 $\lambda^{3}$-tetrazolo[1,5-b][1,2]benziodazole 6 (ellipses are shown at $50 \%$ probability) with selected bond distances and angles. (b) Intra- and intermolecular secondary bonding in 6. 
The structural data revealed the expected distorted T-shaped geometry with an N-I-O bond angle of $161.9^{\circ}$ - even more acute than in the $I$-hydroxy precursor. The lengths of the HV bonds I-N and I-O were respectively 2.20 and $2.14 \AA$, while the length of the I-C bond was $2.12 \AA$, all within the typically observed ranges in similar heterocyclic compounds with an I(III) atom in the ring, e.g., the previously reported $I$ acetoxybenziodazole. ${ }^{53}$ When compared to the I-N $(2.37 \AA)$ and I-O (1.97 $⿱$ ) bond distances in 5 it was noted that in 6 , the I-N bond was shorter by $c a$. $7 \%$ while the I-O bond was longer by almost $9 \%$. Additional intermolecular I...O interactions (I1-O2) were also observed in the dimeric motifs of BIAT-OAc 6.

When the $I$-acetoxy derivative BIAT-OAc 6 was refluxed for 10 min (until dissolved) in methanol, a new HV iodine(III) product was formed, namely 5-methoxy-5H-5 $\lambda^{3}$-tetrazolo[1,5-b][1,2]benziodazole, BIAT-OMe 8 (Scheme 1). It was found to be stable at $-20^{\circ} \mathrm{C}$ for several weeks and was characterized by ${ }^{1} \mathrm{H}$ and ${ }^{13} \mathrm{C}$ NMR spectroscopy, ESI-HRMS, and single-crystal X-ray crystallography (Figure 4). Similar to the other BIAT derivatives, the structure of BIAT-OMe featured a distorted T-shaped geometry around the HV iodine(III) atom, with an N-I-O bond angle of $165.01^{\circ}$. The lengths of the HV bonds I-N and I-O bonds were 2.28 and $2.01 \AA$, respectively, and that of the regular covalent I-C bond was $2.12 \AA$, similar to reported structures of $I$-isopropoxybenziodazoles. ${ }^{53}$ Additional intermolecular interactions between N1 and N2 of the tetrazole ring and the iodine atom from an adjacent molecule were observed in the dimeric motifs of BIAT-OMe 8 (Figure 4b), resulting in pseudo-pentacoordinated HV iodine(III) centers. Interestingly, no intermolecular I-O interactions could be discerned. 
a)

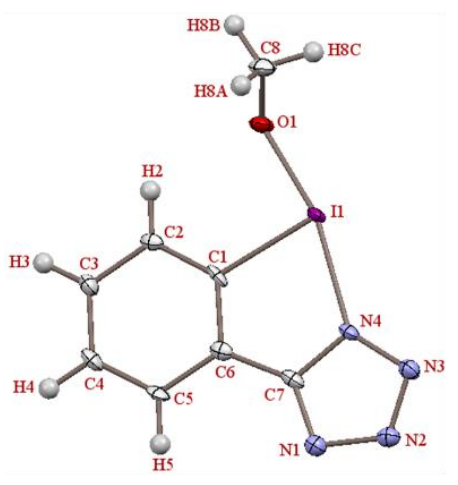

b)

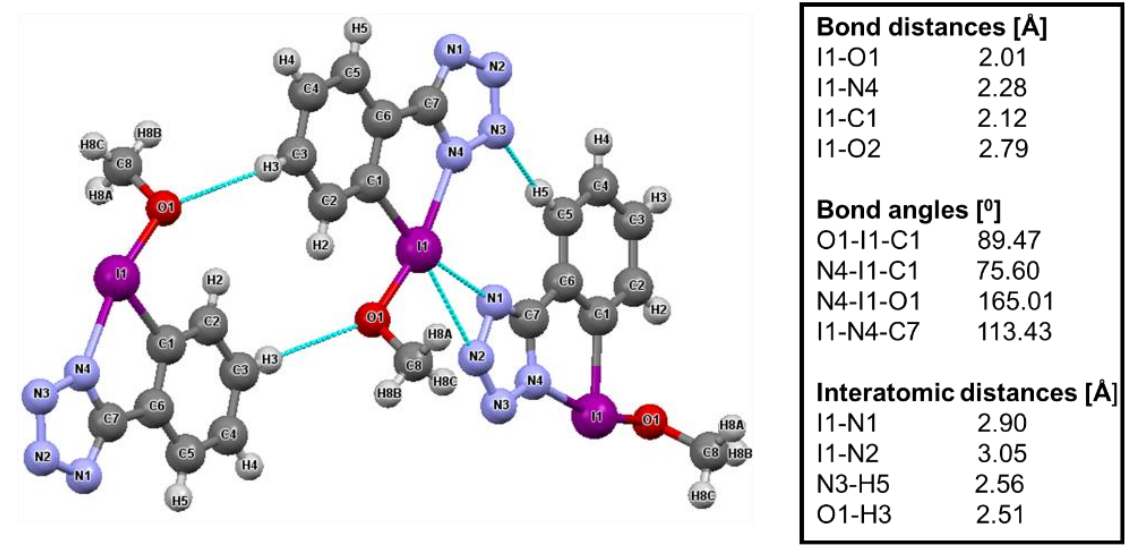

Figure 4. (a) Crystal structure of 5-methoxy-5H-5 $\lambda^{3}$-tetrazolo[1,5-b][1,2]benziodazole 8 (ellipses are shown at $50 \%$ probability) with bond distances and angles. (b) Intra- and intermolecular secondary bonding in 8.

Tetrazoles have found significant applications in coordination chemistry, ${ }^{59,76,77}$ photography, specialty explosives, and in drug synthesis. ${ }^{78-81}$ The last application is due to the fact that tetrazoles are metabolically (hydrolytically) stable analogues of carboxylate esters. ${ }^{82,83}$ Hence, the synthesis of substituted tetrazoles and the ability to incorporate tetrazole moieties directly into a substrate are of great significance and interest. Previously, we have demonstrated the successful transfer of tetrazole groups to various olefins using HV iodine(III) compounds with tetrazole ligands. ${ }^{55,84}$ Inspired by recent work by Loh and co-authors on the copper-catalyzed oxyazidation of styrenes by $I$-azidobenziodoxole, ${ }^{85}$ we explored the possibility to conduct chloroterazolylation of alkenes using BIAT-Cl 4 (Scheme 1). The simultaneous introduction of tetrazole and alkyl chloride functionalities may be advantageous and may enable further functionalizations by well-established nucleophilic substitution reactions.

To optimize the reaction conditions for the chlorotetrazolylation of alkenes with $\mathbf{4}$, cyclohexene was chosen as a model substrate (Table 2). The reactions were conducted in DCE at $25^{\circ} \mathrm{C}$. In the absence of $\mathrm{Cu}(\mathrm{OTf})_{2}$, the desired product was obtained in trace amounts only (entry 1$)$. When $\mathrm{Cu}(\mathrm{OTf})_{2}(2 \mathrm{~mol} \%$ vs. alkene) was used as the catalyst, it was gratifying to find out that after $1 \mathrm{~h}$, the chlorotetrazolylation product 9 was obtained in $33 \%$ yield (entry 2). The yield of 9 was further improved to $52 \%$ by extending 
the reaction time to $5 \mathrm{~h}$ (entry 3$)$. The maximum yield of $\mathbf{9}(78 \%)$ was obtained when the amount of catalyst was increeased to 10 mol \% va. The reactants (entry 4). Substituting DCE for other solvents, such as $\mathrm{CH}_{3} \mathrm{CN}$, DMF, or THF did not imporve the reaction outcome (entries 5-7). The particularly low yield (15\%) observed when the reaction was carried out in THF (entry 7), was likely owing to the the low solubility of both 4 and $\mathrm{Cu}(\mathrm{OTf})_{2}$ in that solvent.

Table 2. Optimization of reaction conditions for addition of BIAT-Cl 4 to cyclohexene.

\begin{tabular}{|c|c|c|c|}
\hline & (0.2 mmol) & & 9 \\
\hline$\#$ & $\mathrm{Cu}(\mathrm{OTf})_{2}[\mathrm{~mol} \%]$ & Solvent & Isolated yield [\%] \\
\hline 1 & 0 & DCE & Trace \\
\hline 2 & 2 & “ & 33 \\
\hline 3 & “ & “ & $52^{a}$ \\
\hline 4 & 10 & “ & 78 \\
\hline 5 & “ & $\mathrm{CH}_{3} \mathrm{CN}$ & 37 \\
\hline 6 & “ & $\mathrm{DMF}$ & 53 \\
\hline 7 & “ & THF & 15 \\
\hline
\end{tabular}

With the conclusion of the optimization studies, the scope of the reaction with respect to the substrates was investigated next (Scheme 2). A variety of alkenes reacted smoothly to afford, in excellent yields, the desired products of chlorotetrazolylation (9-14), all of which were characterized by ${ }^{1} \mathrm{H}$ and ${ }^{13} \mathrm{C}$ NMR spectroscopy, as well as ESI-HRMS (SI). 
Scheme 2. Scope of the copper-catalyzed chlorotetrazolylation of various alkenes with isolated yields.

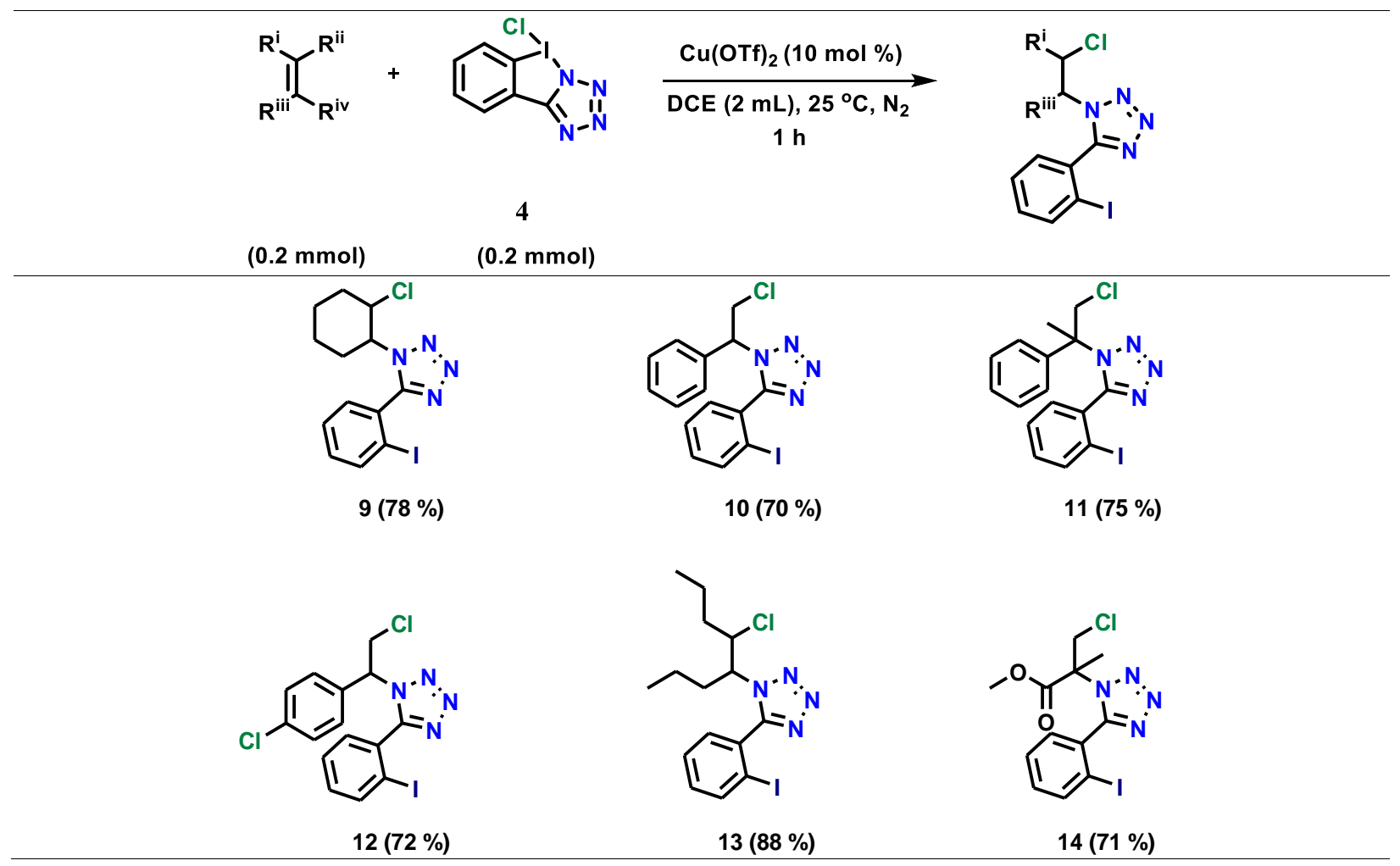

It was recently shown that HV iodine(III) compounds with tetrazole ligands (both the acyclic compounds $\mathrm{C}_{6} \mathrm{H}_{5} \mathrm{I}\left(\mathrm{N}_{4} \mathrm{CR}\right)_{2}{ }^{55}$ and the pseudocyclic derivative, (2-(1H-tetrazol-5yl)phenyl)(hydroxy)iodonium tosylate ${ }^{56}$ are strong oxidants and these studies were logically extended to BIAT derivatives. Thioanisole was chosen as the substrate and the reactions were conducted at room temperature in $\mathrm{CD}_{3} \mathrm{CN}$ using, in all cases, 2 eq of the $\mathrm{HV}$ iodine(III)-based oxidant (4-6 and 8). The oxidation with 4 was fast (virtually complete within $c a .2 \mathrm{~min}$ ) and it afforded the sulfoxide $\mathbf{1 5}$ as the main product. Under these conditions, the chlorination products of thioanisole and the sulfoxide 15, i.e., compounds 16 and 17, respectively, were also observed (Scheme 3, entry 1). Most likely, the O-containing products were formed due to the presence of small unknown amount of water in the reaction solvent. In order to achieve better reproducibility, all further reactions were conducted in $\mathrm{CD}_{3} \mathrm{CN}$ containing deliberately added water $(5 \%(\mathrm{v} / \mathrm{v}))$. In this solvent, the reaction of thioanisole with 4 afforded - once again, within ca. $2 \mathrm{~min}$ - the sulfoxide $\mathbf{1 5}$ as well as the product of its further oxidation, i.e., the sulfone $\mathbf{1 8}$ 
(entry 2). The oxidations with all other studied BIAT-based oxidants $(\mathbf{5}, \mathbf{6}$, and $\mathbf{8})$ were markedly slower (entries 3-5) and yielded the sulfoxide $\mathbf{1 5}$ as the main product. The outcomes of all studied reactions are summarized in Scheme 3.

Scheme 3. Oxidation of thioanisole to $\mathbf{1 5}$ (or other products, which are specified) using BIAT-X 4-6 and 8 at room temperature in the dark.

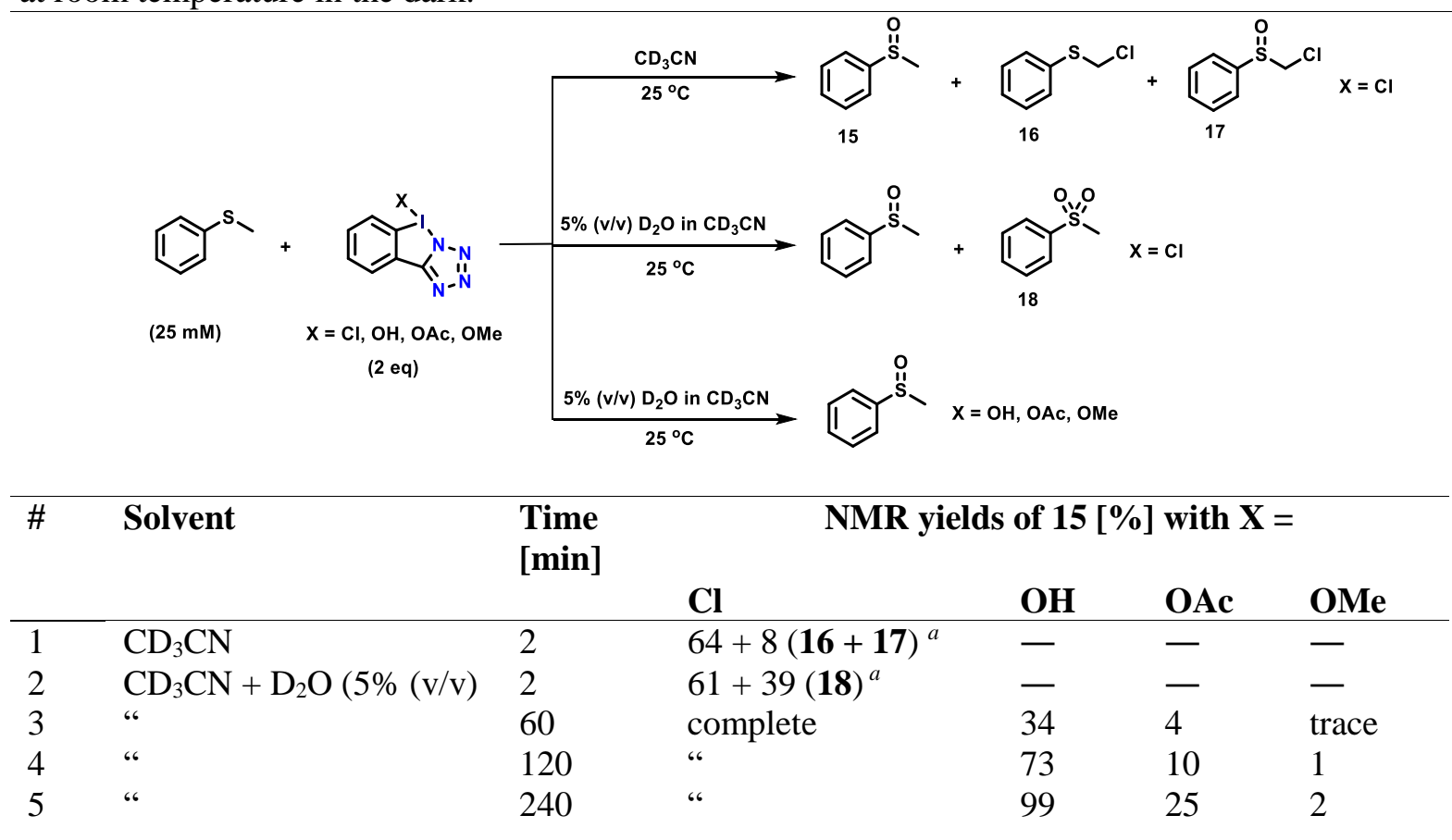

${ }^{a}$ The numbers in parenthesis refer to the observed products shown in the reaction scheme.

The identities of all products shown in Scheme 3 were confirmed by GC-MS after the reactions were complete. It is noteworthy that the reaction mixtures were heterogeneous, and it is plausible to assume that the yields of the products could be highly dependent on the degree of dispersion of the oxidants and the efficiency of stirring.

Certain HV iodine(III) compounds are known for their explosive nature and their exothermic degradation upon heating or even friction, ${ }^{86}$ but to the best of our knowledge, systematic studies and correlations between structure and stability have not yet been published. As mentioned, both BIAT-Cl 4 
and BIAT-OAc 6 are highly oxidizing. Moreover, we have demonstrated ${ }^{55,56}$ that when tetrazoles (which are intrinsically unstable and energetic compounds ${ }^{78,80,81}$ ) are coordinated to HV iodine(III) centers, the formed compounds are particularly prone to decompose upon heating. These initial findings stimulated the studying of the thermal properties of BIAT derivatives, which was accomplished by simultaneous differential scanning calorimetry and thermogravimetric analysis (SDT). Samples were heated from $25^{\circ} \mathrm{C}$ to $550{ }^{\circ} \mathrm{C}$ at a rate of $5{ }^{\circ} \mathrm{C} \mathrm{min}{ }^{-1}$ under a continuous flow of inert gas $\left(\mathrm{N}_{2}\right)$. The enthalpies of decomposition $\left(\Delta H_{d e c}\right)$ were calculated by integrating the identified exothermic peaks in the DSC thermograms. First, the thermal stability of BIAT-Cl $\mathbf{4}$ was investigated, for it was known to be particularly reactive, especially when mixed with reducing agents (vide supra). The TGA curve of 4 revealed a steep weight loss at $135^{\circ} \mathrm{C}$ with a spike, which is commonly seen when typical explosives are subjected to this thermal analysis. A strongly exothermic peak was observed in the DSC thermogram and the value of $\Delta H_{\text {dec }}$ was determined to be two-fold higher than of the parent monovalent iodine-containing tetrazole 2 (-209 and $-108 \mathrm{~J} \mathrm{~g}^{-1}$, respectively). The thermal stability and decomposition of all other BIAT derivatives were also examined (Figure S3) and the results are summarized in Table 3. In addition to the enthalpies of decomposition, the values of $\mathrm{T}_{\mathrm{d} 10}$ and $\mathrm{T}_{\mathrm{d} 50}$ are listed, i.e., the temperatures, at which respectively $10 \%$ and $50 \%$ of the original mass was lost.

Table 3. Decomposition temperatures and enthalpies of degradation of BIAT compounds and the parent monovalent iodine-containing tetrazole.

\begin{tabular}{|c|c|c|c|c|}
\hline Tetrazole & $\mathbf{T}_{\mathrm{d} 10}\left[{ }^{\circ} \mathrm{C}\right]$ & $\mathbf{T}_{\mathrm{d} 50}\left[{ }^{\circ} \mathrm{C}\right]$ & $\Delta \mathbf{H}_{\operatorname{dec}}\left[\mathrm{J} \mathrm{g}^{-1}\right]$ & $\Delta \mathbf{H}_{\text {dec }}\left[\mathrm{kJ} \mathrm{mol}^{-1}\right]$ \\
\hline 2 & 217 & 275 & -108 & -29.4 \\
\hline BIAT-CI (4) & 135 & 135 & -209 & -64.1 \\
\hline BIAT-OH (5) & 217 & 243 & -210 & -60.5 \\
\hline BIAT-OAc (6) & 200 & 209 & -440 & -145.2 \\
\hline
\end{tabular}


BIAT-OMe (8) $\quad 149 \quad 236 \quad-644 \quad-194.5$

The hydroxy derivative 5 had a similar $\Delta H_{d e c}$ of $-210 \mathrm{~J} \mathrm{~g}^{-1}$ (entry 3). However, the decompositions of the compound with an exocyclic carboxylate (acetoxy) ligand, BIAT-OAc (-440 J g $\left.\mathrm{g}^{-1}\right)$, and particularly of the methoxy derivative BIAT-OMe $\left(-644 \mathrm{~J} \mathrm{~g}^{-1}\right)$ were very exothermic.

All synthesized BIAT derivatives should be handled with extreme care and should be stored as small batches because triggers such as elevated temperature and friction (e.g., with metal spatulas) can lead to violent explosion, which occurred in our labs. Handling and storage recommendations are included in the SI. The discovery of BIAT derivatives will likely expand the utility of HV iodine(III) compounds as propellants and in ammunition.

\section{CONCLUSIONS}

We report the synthesis of novel HV iodine(III) compounds comprising fused tetrazoles, and benziodazole (BIAT) rings, with various ligands coordinated to the I(III)center. BIATs 4-6 and $\mathbf{8}$ were characterized using ${ }^{1} \mathrm{H}$ and ${ }^{13} \mathrm{C}$ NMR spectroscopy, ESI-HRMS, and X-ray crystallography. BIAT-Cl (4) was found to be functional for tetrazolylation reaction using $\mathrm{Cu}(\mathrm{OTf})_{2}$ as catalyst. To assess and compare BIATs 4-6 and $\mathbf{8}$ oxidizing ability, a model oxidation reaction of thioanisole was explored and it was observed that $\mathbf{4}$ not only oxidized thioanisole instantaneously, but also produced chlorinated side-products. Furthermore, thermal analysis of these HV iodine(III) compounds was performed and the enthalpies of decomposition $\left(\Delta H_{d e c}\right)$ were measured using SDT. BIAT-OMe 8 was noticed to be extremely energetic with the heat of degradation of $-644 \mathrm{~J} \mathrm{~g}^{-1}$.

\section{ACKNOWLEDGMENTS}


The authors gratefully acknowledge financial support from the National Science Foundation (NSF) through a CAREER grant (CHE-1455200) to NVT. This work was completed while NVT was serving at the NSF. The members of the staff at the Nanotech Institute at the University of Texas at Dallas are acknowledged for SDT measurements.

\section{REFERENCES}

(1) Willgerodt, C. J. Prakt. Chem. 1886, 33, 154.

(2) Mooney, R. C. L. Z. Kristallogr. 1935, 90, 143.

(3) Mooney, R. C. L. Z. Kristallogr. 1939, 100, 519.

(4) Pimentel, G. C. J. Chem. Phys. 1951, 19, 446.

(5) Hach, R. J.; Rundle, R. E. J. Am. Chem. Soc. 1951, 73, 4321.

(6) Musher, J. I. Angew. Chem. Int. Ed. 1969, 8, 54.

(7) Varvoglis, A. Organic Compounds of Polycoordinated Iodine; Wiley-VCH: Weinheim, 1992.

(8) Varvoglis, A. Hypervalent Iodine in Organic Synthesis; Academic Press: San Diego, 1997.

(9) Willgerodt, C. Die Organischen Verbindungen mit Mehrwertigem Jod; Ferdinand Enke: Stuttgart, 1914.

(10) Wirth, T. Hypervalent Iodine Chemistry: Modern Developments in Organic Synthesis; Springer: Berlin, 2003.

(11) Zhdankin, V. V. Hypervalent Iodine Chemistry: Preparation, Structure and Synthetic Applications of Polyvalent Iodine Compounds; Wiley: Chichester, 2014.

(12) Banks, D. F. Chem. Rev. 1966, 66, 243.

(13) Koser, G. F. In Supplement D: The Chemistry of Halides, Pseudohalides and Azides, Part 1; Patai, S., Rappoport, Z., Eds.; Wiley: Chichester, 1983; Vol. 1, p 721.

(14) Moriarty, R. M.; Prakash, O. Acc. Chem. Res. 1986, 19, 244.

(15) Muraki, T.; Togo, H.; Yokoyama, M. Rev. Heteroatom Chem. 1997, 17, 213.

(16) Sandin, R. B. Chem. Rev. 1943, 32, 249.

(17) Stang, P. J.; Zhdankin, V. V. Chem. Rev. 1996, 96, 1123.

(18) Vaish, A.; Tsarevsky, N. V. In Main Group Strategies towards Functional Organic Materials; Baumgartner, T., Jaekle, F., Eds.; Wiley: 2018, p 483.

(19) Varvoglis, A. In Synthesis 1984, p 709.

(20) Yoshimura, A.; Zhdankin, V. V. Chem. Rev. 2016, 116, 3328.

(21) Zhdankin, V. V.; Protasiewicz, J. D. Coord. Chem. Rev. 2014, 275, 54.

(22) Zhdankin, V. V.; Stang, P. J. Chem. Rev. 2002, 102, 2523.

(23) Zhdankin, V. V.; Stang, P. J. Chem. Rev. 2008, 108, 5299.

(24) Meyer, V.; Wachter, W. Ber. 1892, 25, 2632.

(25) Willgerodt, C. J. Prakt. Chem. 1894, 49, 466.

(26) Keefer, R. M.; Andrews, L. J. J. Am. Chem. Soc. 1959, 81, 2374.

(27) Andrews, L. J.; Keefer, R. M. J. Am. Chem. Soc. 1959, 81, 4218.

(28) Amey, R. L.; Martin, J. C. J. Org. Chem. 1979, 44, 1779.

(29) Legault, C. Y.; Prevost, J. Acta Crystallogr. E. 2012, 68, 1238. 
(30) Geary, G. C.; Hope, E. G.; Singh, K.; Stuart, A. M. ChemComm 2013, 49, 9263.

(31) Matoušek, V.; Pietrasiak, E.; Schwenk, R.; Togni, A. J. Org. Chem. 2013, 78, 6763.

(32) Ilchenko, N. O.; Tasch, B. O. A.; Szabó, K. J. Angew. Chem. Int. Ed. 2014, 53, 12897.

(33) Braddock, D. C.; Cansell, G.; Hermitage, S. A.; White, A. J. P. ChemComm 2006, 49, 1442.

(34) Baker, G. P.; Mann, F. G.; Sheppard, N.; Tetlow, A. J. J. Chem. Soc. 1965, 3721.

(35) Etter, M. C. J. Am. Chem. Soc. 1976, 98, 5326.

(36) Mocci, F.; Uccheddu, G.; Frongia, A.; Cerioni, G. J. Org. Chem. 2007, 72, 4163.

(37) Ochiai, M.; Sueda, T.; Miyamoto, K.; Kiprof, P.; Zhdankin, V. V. Angew. Chem. Int. Ed. 2006, 45, 8203.

(38) Ochiai, M.; Ito, T.; Masaki, Y.; Shiro, M. J. Am. Chem. Soc. 1992, 114, 6269.

(39) Ochiai, M.; Ito, T.; Takahashi, H.; Nakanishi, A.; Toyonari, M.; Sueda, T.; Goto, S.; Shiro, M. J. Am. Chem. Soc. 1996, 118, 7716.

(40) Sueda, T.; Takeuchi, Y.; Suefuji, T.; Ochiai, M. Molecules 2005, 10, 195.

(41) Zhdankin, V. V.; Kuehl, C. J.; Krasutsky, A. P.; Formaneck, M. S.; Bolz, J. T. Tetrahedron Lett. 1994, 35, 9677.

(42) Krasutsky, A. P.; Kuehl, C. J.; Zhdankin, V. V. Synlett 1995, 1995, 1081.

(43) Akai, S.; Okuno, T.; Egi, M.; Takada, T.; Tohma, H.; Kita, Y. Heterocycles 1996, 42, 47.

(44) Zhdankin, V. V.; Kuehl, C. J.; Krasutsky, A. P.; Bolz, J. T.; Mismash, B.; Woodward, J. K.; Simonsen, A. J. Tetrahedron Lett. 1995, 36, 7975.

(45) Frei, R.; Courant, T.; Wodrich, M. D.; Waser, J. Chem. Eur. J. 2015, 21, 2662.

(46) Niedermann, K.; Welch, J. M.; Koller, R.; Cvengroš, J.; Santschi, N.; Battaglia, P.; Togni, A. Tetrahedron 2010, 66, 5753.

(47) Viktor, V. Z. Curr. Org. Synth. 2005, 2, 121.

(48) Nemykin, V. N.; Maskaev, A. V.; Geraskina, M. R.; Yusubov, M. S.; Zhdankin, V. V. Inorg. Chem. 2011, 50, 11263.

(49) Koser, G. F.; Sun, G.; Porter, C. W.; Youngs, W. J. J. Org. Chem. 1993, 58, 7310.

(50) Koposov, A. Y.; Litvinov, D. N.; Zhdankin, V. V.; Ferguson, M. J.; McDonald, R.; Tykwinski, R. R. Eur. J. Org. Chem. 2006, 2006, 4791.

(51) Balthazor, T. M.; Miles, J. A.; Stults, B. R. J. Org. Chem. 1978, 43, 4538.

(52) Wolf, W.; Steinberg, L. ChemComm 1965, 449.

(53) Zhdankin, V. V.; Arbit, R. M.; McSherry, M.; Mismash, B.; Young, V. G. J. Am. Chem. Soc. 1997, 119,7408 .

(54) Vlasenko, Y. A.; Yusubov, M. S.; Shafir, A.; Postnikov, P. S. Chem. Heterocycl. Compd. 2020, 56, 854.

(55) Kumar, R.; Vaish, A.; Runčevski, T.; Tsarevsky, N. V. J. Org. Chem. 2018, 83, 12496.

(56) Vaish, A.; Sayala, K. D.; Tsarevsky, N. V. Tetrahedron Lett. 2019, 150995.

(57) Willgerodt, C. J. Prakt. Chem. 1893, 26, 357.

(58) Willgerodt, C. J. Prakt. Chem. 1894, 49, 466.

(59) Andrejević, T. P.; Nikolić, A. M.; Glišić, B. Đ.; Wadepohl, H.; Vojnovic, S.; Zlatović, M.; Petković, M.; Nikodinovic-Runic, J.; Opsenica, I. M.; Djuran, M. I. Polyhedron 2018, 154, 325.

(60) Cao, Y.; Kumar, R.; Tsarevsky, N. V. Macromol. Chem. Phys. 2019, 220, 1800471

(61) Toehl, A. Ber. 1893, 26, 2949.

(62) Karele, B. Y.; Neiland, O. Y. Latv. PSR Zin. Akad. Vest. 1970, 587.

(63) Keefer, R. M.; andrews, L. J. J. Am. Chem. Soc. 1958, 80, 177.

(64) Li, X.-Q.; Zhang, C. Synthesis 2009, 2009, 1163.

(65) Zhao, X.-F.; Zhang, C. Synthesis 2007, 2007, 551.

(66) Wang, M.; Zhang, Y.; Wang, T.; Wang, C.; Xue, D.; Xiao, J. Org. Lett. 2016, 18, 1976.

(67) Birchall, T.; Frampton, C. S.; Kapoor, P. Inorg. Chem. 1989, 28, 636.

(68) Lee, C.-K.; Mak, T. C. W.; Li, W.-K.; Kirner, J. F. Acta Cryst. 1977, B33, 1620.

(69) Gougoutas, J. Z.; Clardy, J. C. J. Solid State Chem. 1972, 4, 226.

(70) Shefter, E.; Wolf, W. Nature 1964, 203, 512. 
(71) Yoshimura, A.; Shea, M. T.; Makitalo, C. L.; Jarvi, M. E.; Rohde, G. T.; Saito, A.; Yusubov, M. S.; Zhdankin, V. V. Beilstein J. Org. Chem. 2018, 14, 1016.

(72) Balthazor, T. M.; Godar, D. E.; Stults, B. R. J. Org. Chem. 1979, 44, 1447.

(73) Kalim, J.; Duhail, T.; Le, T.-N.; Vanthuyne, N.; Anselmi, E.; Togni, A.; Magnier, E. Chem. Sci. 2019, 10, 10516.

(74) Zhdankin, V. V.; Koposov, A. Y.; Su, L.; Boyarskikh, V. V.; Netzel, B. C.; Young, V. G. Org. Lett. 2003, 5, 1583.

(75) Aertker, K.; Rama, R. J.; Opalach, J.; Muñiz, K. Adv. Synth. Catal. 2017, 359, 1290.

(76) Aromí, G.; Barrios, L. A.; Roubeau, O.; Gamez, P. Coord. Chem. Rev. 2011, 255, 485.

(77) Lodyga-Chruścińska, E. Coord. Chem. Rev. 2011, 255, 1824.

(78) Butler, R. N. In Comprehensive Heterocyclic Chemistry, 4A; Katritzky, A. R., Rees, C. W., Eds.; Pergamon: Oxford, 1984; Vol. 5, p 791.

(79) Butler, R. N. In Comprehensive Heterocyclic Chemistry II; Katritzky, A. R., Rees, C. W., Scriven, E. F. V., Eds.; Elsevier: Oxford, 1996; Vol. 4, p 621.

(80) Ostrovskii, V. A.; Koldobskii, G. I.; Trifonov, R. E. In Comprehensive Heterocyclic Chemistry III; Katritzky, A. R., Ramsden, C. A., Scriven, E. F. V., Taylor, R. J. K., Eds.; Elsevier: Oxford, 2008; Vol. 4, p 257.

(81) Benson, F. R. Chem. Rev. 1947, 41, 1.

(82) Singh, H.; Singh Chawla, A.; Kapoor, V. K.; Paul, D.; Malhotra, R. K. In Progress in Medicinal Chemistry; Ellis, G. P., West, G. B., Eds.; Elsevier: 1980; Vol. 17, p 151.

(83) Herr, R. J. Bioorg. Med. Chem. 2002, 10, 3379.

(84) Kumar, R.; Sayala, K. D.; Cao, Y.; Tsarevsky, N. V. J. Polym. Sci. 2020, 58, 172.

(85) Lu, M.-Z.; Wang, C.-Q.; Loh, T.-P. Org. Lett. 2015, 17, 6110.

(86) Boelke, A.; Vlasenko, Y. A.; Yusubov, M. S.; Nachtsheim, B. J.; Postnikov, P. S. Beilstein J. Org. Chem. 2019, 15, 2311. 